\title{
DESign, DEVELOPMENT \& IMPLEMENTATION OF ONTOLOGICAL KNOWLEDGE BASED SYSTEM FOR Automotive ASSEMBLy LiNeS
}

\author{
Muhammad Baqar Raza, Robert Harrison \\ Wolfson School of Mechanical and Manufacturing Engineering \\ Loughborough University, Loughborough LE11 3TU, UK \\ mmbrmelboro.ac.uk
}

\begin{abstract}
Dynamism and uncertainty are genuine threats for current high technology organisations. Capability to change is the crux of sustainability of current large organisations. Modern manufacturing philosophies, including agile and lean, are not enough to be competitive in global market therefore a new emerging paradigm i.e. reconfigurable manufacturing systems is fast emerging to complement the application of lean and agile manufacturing systems. Product, Process and Resource (PPR) are the core areas in an engineering domain of a manufacturing enterprise which are tightly coupled with each other. Change in one (usually product) affects the others therefore engineering change management activity has to tackle $P P R$ change effects. Current software applications do not provide an unequivocal infrastructure where $P P R$ can be explicitly related. It follows that reconfigurable techniques can be further complemented with the help of knowledge based systems to design, engineer, manufacture, commission and change existing processes and resources against changed products.
\end{abstract}

\section{KEY WORDS}

Knowledge Based System, Ontology, Knowledge Management, Reconfigurable Assembly Systems, Change Management.

\section{INTRODUCTION}

Reconfigurable Assembly Systems (RAS), a subset of Reconfigurable Manufacturing Systems (RMS), facilitate enterprises to rapidly respond to changes in today's unpredictable and dynamic global markets. One of the key success factors for the effective use of RAS is methods and tools that can rapidly configure and reconfigure assembly systems driven by changing product requirements. The focus of the current research is the development of a suitable knowledge based system for knowledge sharing and reuse. Relational knowledge among Products, Processes and Resources is the ultimate crux in engineering domain of a technology organisation.

Ontologies are an important field related to knowledge capture, representation, management and reuse as well as quickly searching on the web. Initially ontologies were used to share knowledge and information in the area of medical information processing. Presently, ontologies have become prominent because they offer a mutual and general understanding of the domain of interest to facilitate communication among the application system and individuals. In the current research work, it is intended to develop a method for using a knowledge management tool so as to create an axiom-controlled ontology to define prospects of the knowledge model and its plan to control the actions of the model for use in a manufacturing environment. The authors argue for the need of a flexible, meta-data driven approach to address requirements for the use of knowledge bases in industrial settings and present a lightweight ontological knowledge based system as a decision 
support tool in assembly line design and/or reconfiguration activity. Adding up to this discussion, it also mentions a manufacturing skill data formation as a part of organisational knowledge structure using an ontological approach. Here organisational knowledge means a combined engineering knowledge of a firm which may be precise in the form of record or document or tacit knowledge hidden in the form of intellectual capital of the organisations. Though engineering domain is a vast area however the main engineering entities dealt in the developed system are Product, Process and Resource (PPR).

Automotive sector is under pressure to produce new customised automobile models almost every year. Based on the results derived from the international Delphi survey, a specially formed committee on Visionary Manufacturing Challenges in USA, identified six "grand" challenges for manufacturers that represent gaps between current practices and the vision of manufacturing in 2020. The committee, which worked under Commission on Engineering and Technical Systems, identified following 'grand' challenges for manufacturing (US National Research Council 1998):

1) Achieve concurrency in all operations; 2) Integrate human and technical resources to enhance workforce performance and satisfaction; 3) "Instantaneously" transform information gathered from a vast array of diverse sources into useful knowledge for making effective decisions; 4) Reduce production waste and product environmental impact to "near zero"; 5) Reconfigure manufacturing enterprises rapidly in response to changing needs and opportunities; and 6) Develop innovative manufacturing processes and products with a focus on decreasing dimensional scale.

The committee recommended the following key strategic technology and research areas as the most important requirement for meeting the grand challenges (US National Research Council 1998): 1) Adaptable, integrated systems, processes and integrated equipment that can be readily reconfigured; 2) System synthesis, modelling and simulation for all manufacturing processes; and 3) Technologies to convert information into knowledge for effective decision making.

The committee recommendations classified (i) enterprise reconfiguration ability and (ii) decision making knowledge, as two breakthrough technologies that would accelerate progress in addressing the aforementioned grand challenges. In addition, the committee recommended that the most effective research would be multidisciplinary and grounded in knowledge of manufacturing strategies, planning and operations because manufacturing is inherently multidisciplinary and involves a complicated mix of people, systems, processes and equipment (US National Research Council 1998). The recommendations for the industry and government included adaptation and reconfiguration of manufacturing processes rapidly for the production of diverse and customised products. It also included adaptation and reconfiguration of manufacturing enterprises to enable the formation of complex alliances with other organisations.

\section{LITERATURE REVIEW}

A constantly growing number of companies that offer professional services or tools in the knowledge management area reflect the use of knowledge based systems for industrial problems (Davis, 2006). Typical applications of ontologies and rule bases include knowledge and skill management (Staab, 2002) as well as web service and business process management (Fensel et al, 2006). Extensive theoretical studies (Hahn, 2005; Hahn, 2007), prototypes (Stegmüller, 2003; Küsters, 2006), and first successful projects (Syldatke, 2007) emphasise the relevance of these technologies in the area of product lifecycle management (PLM) in particular in the automotive sector. While theoretical issues such as expressiveness and decidability still remain fundamental, non-functional aspects like knowledge base maintainability and security are getting crucial too (Hepp, 2007). 
In the past, many IT systems have been built to support single and focused aspects within the product development process (e.g. car conception, virtual simulation, part tracking etc.) each of these maintaining their own models, structures and semantics about the products and their parts. Nevertheless, all systems do contribute data and information to the final product, i.e. the actual car to be built for the customer. In order to enable flexible changes and adoptions in such a grown infrastructure, especially from a business point of view, there is a strong need to share and exchange such heterogeneous product models with related engineering domains.

There is a rising level of ontology research based on functions of knowledge management and contribution of information and recovery. Some of the selected research projects are briefly described here, it emphasise on some more attractive results from different parts of the ontology research \& development society. IBROW3 introduces 'Broker Service' for data component and reusing over the web and is an ontological knowledge system (IBROW3, 2004). The aim of IBROW3 is to create brokers that are able to organise reusable parts into workable knowledge systems through www. In the knowledge engineering authority, the 'On-To-Knowledge' (OKT, 2004) project has created practical methods and trappings based on an ontological approach, to ease the organisation, share and reuse knowledge. OTK tools support knowledge employees, which are not IT people, to use information of their company repositories in a natural and efficient way. The OTK plan applies ontology to electronically provide information to increase the class of knowledge management in vast and distributed companies. 'PICSEL' (Production dInterfaces a base de Connaissances pour des Services En Ligne) is an information combination system for knowledge sources that are spread and heterogeneous (Goasdoue', 1999). This approach describes information server as knowledge based third party between users and information sources which already exists, comparative to only application domain.

Onto Broker (2004) is an engine which analyses with semantic information mixing ability from 'Ontoprise' (www.ontoprise.com). Through connectors, import and export plan and built-in functions with integration of records is achieved, for example, through existing database data plan can be imported, representing ontology and to connect search engines and applications. Semantic Miner (Moench, 2003; Moench et al, 2003) is recovery platform of knowledge that joins semantic technologies with conventional recovery approach. It is structured like client-server construction and gives recovery information from various statistics basis.

Technological innovation has induced very significant change in industry during recent times. This has impacted significantly on the way that Manufacturing Enterprises (MEs) operate and compete with each other. In general MEs are complex entities: designed, managed and changed by people and the supporting systems; to realise customer and stakeholder requirements; by deploying operational (technological and people) resources in innovative, systematic and timely ways that generate competitive behaviours. Typically MEs have multi purposes and stakeholders it is difficult to decide how best (and therefore near optimally) to design, select and develop the technological systems (such as ERP, PLM and CAD/CAM systems) they deploy. Efficient decision making is crucial in any and particularly manufacturing enterprises. Considering the complexity of the MEs especially the engineering domain, it is intended to provide decision support in as complex an activity as assembly line design / reconfiguration by ontologically transforming the available information into actionable knowledge. As engineering domain of a technology intensive organisation is multi faceted, having multipurpose goal-sets and hundreds of supporting software applications, therefore, restricting the focus on the addressed issue in the declared domain is vital for the success of the research and the developed system. Hence this research focuses on the design and development of a Knowledge Based (KB) system for the assembly line design and reconfiguration activity and the KB system's scope is delimited within 
PPR domains, their interactions and relations among each other, which directly affect this activity.

\section{ONTOLOGY IN KNOWLEDGE BASED SYSTEMS}

An ontology is the working model of entities and interactions in some particular domain of knowledge or practices. An ontology is a set of concepts (such as things, events, and relations) that are specified in some way (such as a specific programming language) in order to create an agreed-upon vocabulary for exchanging information. In the terms of information technology, ontology can be thought as the model for entities and communications in any domain of practice such as electronic commerce, activities for planning etc. Ontology can be used for expressing some fundamental concepts like things, relations and events precise in some other way to manufacture an approved vocabulary for distributing data, over the World Wide Web (Noy and Klein 2004). Providing an ordinary acceptance, Valarakos et al. (2004) said that ontology can be used to make possible distribution and reuse the information and data. The fundamental approach used to make ontology is the process specification language and web based technologies (Schlenoff et al. 2000). Usually the standards of web based technologies that contributes to manufacturing ontology are the XML, the web ontology, the RDF, WSML and XML Metadata Interchange (XMI) format (OMG 2005).

In the course of knowledge utilisation, Dalkir (2005) stressed the importance of a shared context. Abecker et al (2001) proposed knowledge delivery through a formal representation of a generally accepted domain knowledge structure. Gruninger and Atefi (2000) suggested the use of ontology to formalise knowledge in various branches of engineering. It is generally acknowledged that the construction of some domain models (for that is precisely what an ontology is) is, amongst other things, a prerequisite for building knowledge-based systems of any sort (Uschold and Gruninger, 1996).

An ontology is the working model of entities and interactions in some particular domain of knowledge or practices, such as electronic commerce or the activity of planning (Davies et al. 2002). According to specialists at Stanford University (Noy and Klein 2004), ontologies can be used to express 'a set of concepts such as things, events and relations that are specified in some way in order to create an agreed vocabulary for exchanging information, in particular over the world-wide-web (www)'. Apart from providing a common understanding, Valarakos et al. (2004) also argued that ontologies can be used to facilitate dissemination and reuse of information and knowledge.

Service oriented architectures (SOA) have the potential to split the production process down into modules which are independent, self-contained functional units and can be linked to create highly reconfigurable production lines (Raza et al, 2011b). To help the organisational knowledge structure in PPR lifecycle support, the following techniques of ontology are measured as important:

Domain ontology: Arranges concepts, relationships and instance to facilitate occurrence, as well the performance that takes place, in a domain (Van Heijst et al. 1997).

Top-level / Generic ontology: organizes generic domain independent concepts and relations, explicating important semantic distinctions (Sowa 1995).

Ontology function: it carries knowledge of a special domain function (Van Heijst et al.1997). Noy and McGuinness (2000) describe five reasons for development of an ontology:

- to share common understanding of the structure of information amongst people or software agents;

- to enable reuse of domain knowledge; 
- to make domain assumptions explicit;

- to separate domain knowledge from the operational knowledge;

- to analyse domain knowledge.

A high level generalisation of ontology definition as expressed by knowledge management group at the institute AIFB at the University of Karlsruhe (Stumme et al., 2003) is presented, an ontology $\mathrm{O}$ is the following tuple:

$\mathrm{O}:=(\mathrm{S}, \mathrm{A}, \mathrm{KB}$, Lex $)$ consisting of:

- the core ontology S,

- the L-axiom system A,

- the knowledge base $\mathrm{KB}$, and

- the lexicon Lex.

Where as a core ontology ' $\mathrm{S}$ ' is a structure consisting of:

$\mathrm{S}:=(\mathrm{C}, \leq \mathrm{C}, \mathrm{R}, \sigma \leq \mathrm{R})$

- two disjoint sets $\mathrm{C}$ and $\mathrm{R}$ whose elements are called concept identifiers and relation identifiers (or concepts and relations),

- a partial order $\leq_{\mathrm{C}}$ on $\mathrm{C}$, called concept hierarchy or taxonomy,

- a function $\sigma: \mathrm{R} \rightarrow \mathrm{C} \times \mathrm{C}$ called signature, with domain $\operatorname{dom}(\mathrm{r}):=\pi_{1}(\sigma(\mathrm{r}))$ and range $\operatorname{ran}(\mathrm{r}):=\pi_{2}(\sigma(\mathrm{r}))$ with $\mathrm{r} \in \mathrm{R}$,

- a partial order $\leq \mathrm{R}$ on $\mathrm{R}$, called relation hierarchy, where, $\mathrm{r}_{1} \leq \mathrm{R} \mathrm{r}_{2}$ implies $\operatorname{dom}\left(\mathrm{r}_{1}\right) \leq \mathrm{C}$ $\operatorname{dom}\left(\mathrm{r}_{2}\right)$ and $\operatorname{ran}\left(\mathrm{r}_{1}\right) \leq \mathrm{C} \operatorname{ran}\left(\mathrm{r}_{2}\right)$

Given that ontology has the potential to improve knowledge capturing, organisation, sharing and reuse, it was chosen in this research to create a knowledge-based system to support the organisation knowledge framework. Furthermore, using ontologies in the organisational knowledge framework can provide the following advantages:

(i) sharing knowledge domains across the www;

(ii) not relying on a set of rule-based techniques;

(iii) being capable of handling complex and disparate information from different domains.

Eventually, using ontology in the company's knowledge framework may give the following benefits:

- not depending on hard-coded rule-based techniques;

- share knowledge domains across the www;

- capable of handling complex and disparate data from unlike domains.

Modelling an organizational knowledge is a complicated task and needs a group of dissimilar type of ontology derived techniques. To help the organisational knowledge based structure in product progress, the following techniques of ontology are measured as important.

\section{NEED FOR KNOWLEDGE BASES}

The long-term success of any company lies not only in the capabilities and attractiveness of its products but also in the processes used to make products and in processes used to engineer 
change to products and processes (Hammer et al. 1993). To make use of ontologies, knowledge base for semantic mixing of models of product vs. resource capabilities through processes, is essential and addressed in this research.

Agility and Responsiveness: Competition, complexity and continuous change are major challenges of current manufacturing organisations as shown in Figure 1. In order to sustain and remain competitive, it is necessary to devise new methods to exploit ever growing data in the current digitally revolutionised world.

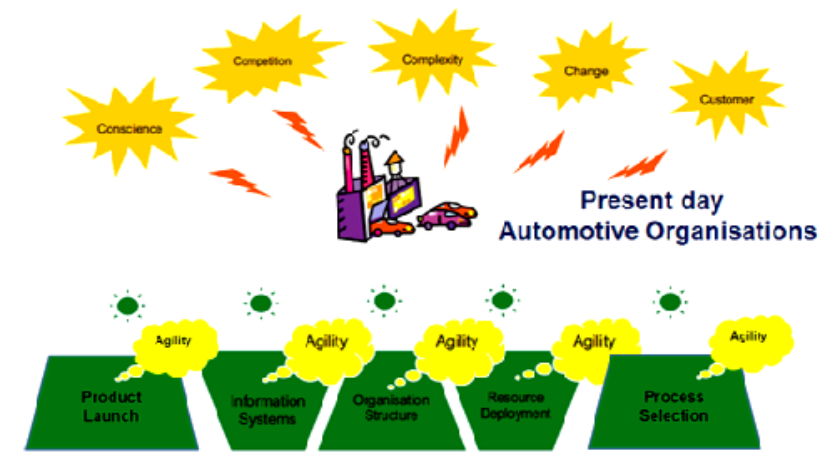

Figure 1. Present day Automotive Organisations (adopted from Chatha, 2004)

There are many other challenges to present day automotive organisations like business competition, complexity of products and processes and resources, rapid changes, and the changing requirements of customers. Although organisations are supported by different expert personnel, information systems and high-tech infrastructure, their non-responsiveness to change will expose them to severe threats that may question their very survival. Thus agility and responsiveness are crucial factors to cope with the current intense business environments as explained in Figure 1. Agility and responsiveness mainly depend upon faster and correct-firsttime decisions. Thus the intangible factor i.e. decision making / support is as important a factor as latest technology infrastructure for the very existence of current organizations.

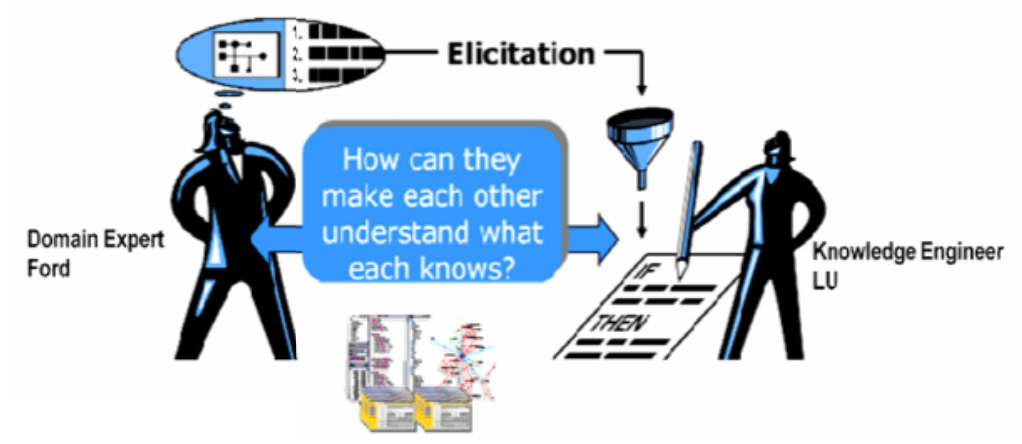

Figure 2. Transforming Information from Domain Expert to Knowledge

The role of a knowledge based system is to translate implicit domain knowledge into usable explicit knowledge. Implicit knowledge is often retained by domain experts and it is difficult to extract and transform into practical knowledge. This task is performed by knowledge based 
systems with the help of knowledge engineer as shown in Figure2. With the growing access to heterogeneous and independent product data repositories, the treatment of differences in the structure and semantics of the data plays a major role in product knowledge systems. Recent research has used ontology as the knowledge base that describes concepts, properties and relations.

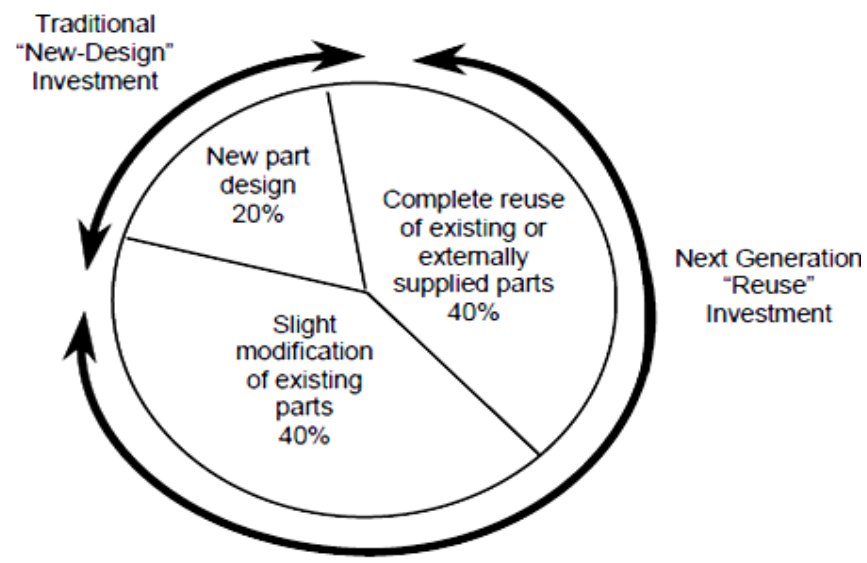

Figure 3. Traditional New Design Investment

A knowledge based system is designed to exploit already existing information and converts it to knowledge. There is a continuous change in PPR domains however the change is always gradual therefore as a rule of thumb, any change in product would require new design of processes and resources only by $20 \%$. Whereas $40 \%$ of the resources would fall under the category 'use-as-is' and the same percentage would require slight modifications as depicted in Figure 3. Therefore there is a need to reuse and exploit existing knowledge rather than redesign and reinvent new information.

\section{ASSEMbly Automation SySTEMS}

Current automation systems fail to meet business requirements (Raza and Harrison, 2011c). Engine congregation line consists of a transportation arrangement that associates mutually a variety of assembly locations (Harrison, 2006). In the manufacturing domain, the relationship between the design phase of a product and its creation on a production line is vital for manufacturing efficiency (Raza et al, 2009).

The assembly locations manage without help of each other; there is no administration pairing between them. Radio frequency identification (RFID) labels are set up in every one pallet for stocking procedure information linked with the assembly branch on the pallet. The route changer known as Diverters or listing stations are positioned at the conveyor crossroads to direct pallets to dissimilar locations or to modify the point of reference of the pallet for the succeeding assembly function (Hahn, 2007). Sensors and motorized stops are used all over the transportation system to track the pallets and express them down dissimilar conveyors as per the data and information kept in every individual pallet. Every fresh assembly arrangement distributed to the end-user, e.g., automotive assembly line, will be self-possessed of an exclusive mixture of such transportation, congregation and test interconnected component (Baker and Maropoulos, 1999). Whilst some components will unavoidably be exclusive to a new function, the greater part (typically $>70 \%$ ) will be stand on the reprocess of preceding perfunctory component. The conventional sequential 
manufacturing approach to the execution of such systems includes the design arrangement of the main mechanical apparatus, in addition of finally commissioning activities, electrics, control systems and finally commissioning activities. So whilst the fundamental mechanism basics are basically modular, slightest from a mechanical viewpoint, the concluding machine, after the calculation of drive arrangement and control arrangement has become really monumental and difficult to modify. The current reconfiguration approach is largely based on the skill and knowledge of engineers rather than the actual process involved. Whenever there is any change in the product it is then essentially engineer's responsibility to examine the needs of the reconfigured system to support the new product (Raza et al, 2011a). To automate (fairly) the task of assembly line configuration / reconfiguration, product and resource (line) link points need to be defined at early stages of design and made available easily to be searched, analysed and implemented on when and where required basis (Raza and Harrison, 2011a).

\section{ASSEMBLY SYSTEM CONFIGURATION AND RECONFIGURATION METHODOLOGY}

A knowledge enriched web-enabled assembly system design framework was reported by Lohse et al. (2004). The methodology includes five concurrent steps that correspond to the agents in the system framework: obtaining the product characteristics (project specification during requirements engineering); generation and specification of process plans (process decomposition agent); generation and specification of conceptual design solutions (conceptual design agents); selection and configuration of system alternatives (embodiment design agents); and evaluation of concepts and system alternatives (service agents). Each step is supported by relevant procedural and declarative knowledge. The same concept is used to develop the KB system with special focus on PPR domains, gathering required information from several sources as shown in Figure 4.

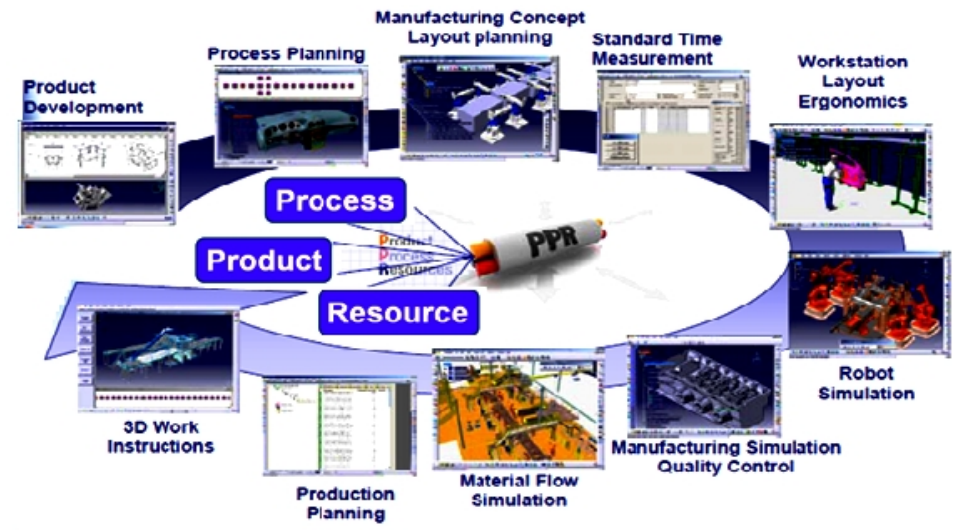

Figure 4. PPR are the core entities in assembly line design / reconfiguration

Three main roles of stakeholders in the design process have been identified: customers who potentially require a new system; system integrators who design and build assembly systems; and equipment suppliers who design and manufacture the equipment modules that constitute assembly systems (Object Management Group, 2003). The customers define requirements for the assembly system in the form of a product model, project, process, and equipment constraints. The system integrator has the key task of defining assembly systems that fulfil the requirements of the customer, using commercially available equipment modules and solutions from different vendors. This involves the specification of the required assembly process, conceptual design of the 
assembly system, equipment selection, configuration, and evaluation. The equipment suppliers provide and suggest suitable equipment solutions.

The key stages of the design process are implemented as independent application modules (agents) that contain their own decision logic, communication facilities and domain knowledge. The framework deploys a representative agent for each participating stakeholder according to their role (Mizoguchi and Kitamura, 2000). These agents provide basic facilities to manage the design process and the interaction with other stakeholders, including sending and receiving of messages as well as initialization and coordination of relevant design tasks. Each distinctive design task within the stakeholders' role is deployed as a separate agent ensuring a high degree of concurrency and a clear separation of the required knowledge during the design process.

The agent based design framework is defined in such a manner as to enable the change of any of the input requirements and to allow the resulting change to be propagated through the decision making process (Laird, 2001). This aspect, combined with a requirement specification methodology that takes into account possible future requirements changes (Hirani, 2004), enables the framework to quickly configure either new systems or reconfigures existing assembly systems according to changed demands.

Virtual verification is done for only potentially problematic stations and most of the stations are left to be checked during the time of installation and commissioning which results problems during commissioning phase (Raza et al, 2010). Manufacturing enterprises need to be responsive in the current volatile environment and a suitable knowledge based system can provide one of the means to be agile and responsive to the sudden unpredictable changes as described in Figure 5.

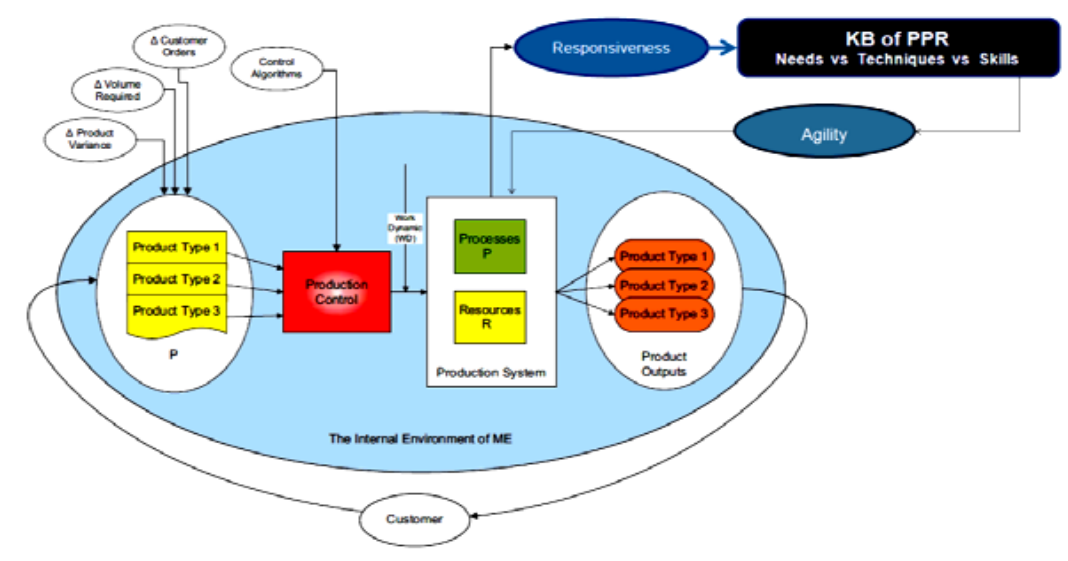

Figure 5. PPR domains vs KB system

The KB system can help transform information into decision making knowledge especially in engineering domain. In automotive sector the knowledge based system can be used to establish relations among important areas i.e. PPR. The knowledge based system must be designed in such a way to accommodate most changes in the processes, resources and products according to the market changes. It also emphasizes the reuse of knowledge and core competencies by suitable alliances to reduce cost and improve efficiency (Gunasekaran, 1998). 


\section{THE PROPOSED SYSTEM}

There have been an increasing number of research projects applying ontological techniques in the context of product development (Roche, 2000; Duineveld et al, 2000; Ciocoiu et al, 2001; Lin and Harding, 2003). However, none of the projects directly address the issues of utilising ontology technique to share assembly knowledge in collaborative and distributed manners especially based on modular techniques.

Fig. 6 represents the reference architecture and explains the concept of the capability based mapping of product requirements and system capabilities. The capability taxonomy connects the product and resource domains together allowing the mapping.

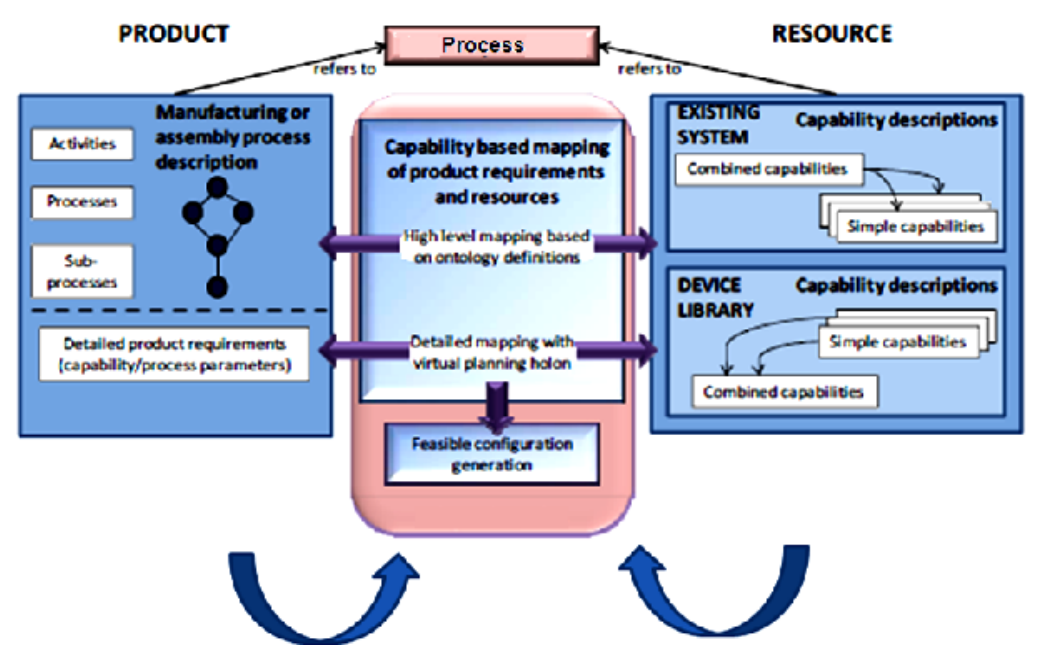

Figure 6. The research methodology: Knowledge based system architecture

The first phase of the work is to link to the existing data in legacy software applications, the project has developed services to automatically extract the appropriate designs, compare them against the product and produce reports for key areas of focus for the new line configuration. In addition to this services are being developed to link this data into the enterprise systems to aid scheduling of the implementation of the line and order of appropriate parts from suppliers. CB tool is required to be used for re-configuration of the engine assembly line. CB tool should be able to access information from multiple applications. CB tool needs to have information of product, process and control logic. Any semantic heterogeneity should be resolved automatically through ontology. CB tool should be able to access instances directly from original locations, mediated / non mediated. Ontology can help automate:

\section{Applications integration relevant to PPR domains}

2. Re-configuration management of assembly line for powertrain assemblage

Ontology to be used for linking databases at Ford through SWSs and getting required information as and when required. Therefore using ontologies separate and distributed sources of vital line information can be both searched and linked in order to troubleshoot lines consisting of multiple vendors' machinery (Raza and Harrison, 2011b). A knowledge based system is a collection of knowledge in the form of "subject-problem-solution" form that pertains to a specific domain. 


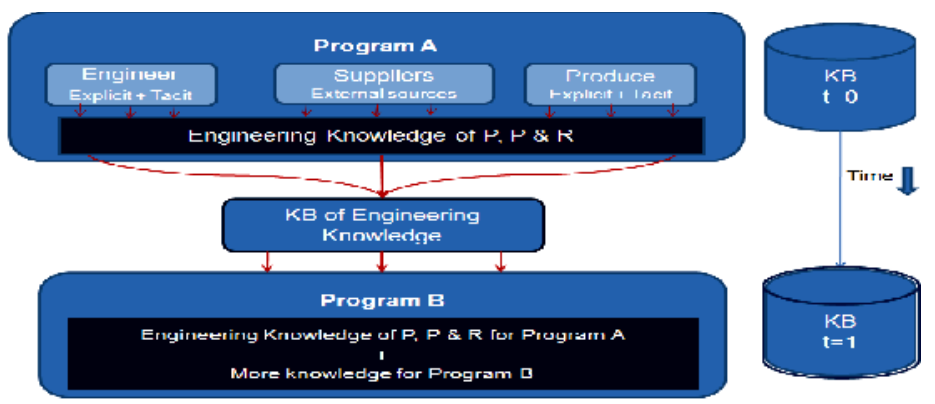

Figure 7. Implementation and usage of the proposed system

The developed system makes use of the PPR information of existing programs to help launch new programs rapidly as shown in Figure 7. The existing information from domain engineers, suppliers and relevant stake holders is stored in the knowledge based system thus making an efficient repository of useful and decision making knowledge which can be used for new programs. Thus a knowledge base is not a stationary application rather it evolves with time.

The system consists of three layers of architecture. The first layer explicitly provides all the knowledge and specification needed for decision making. The second layer extracts the given implicit information, transforms it into an explicit format. The third layer is where the intelligent reasoning takes place which includes generating final configuration as shown in Figure 8.
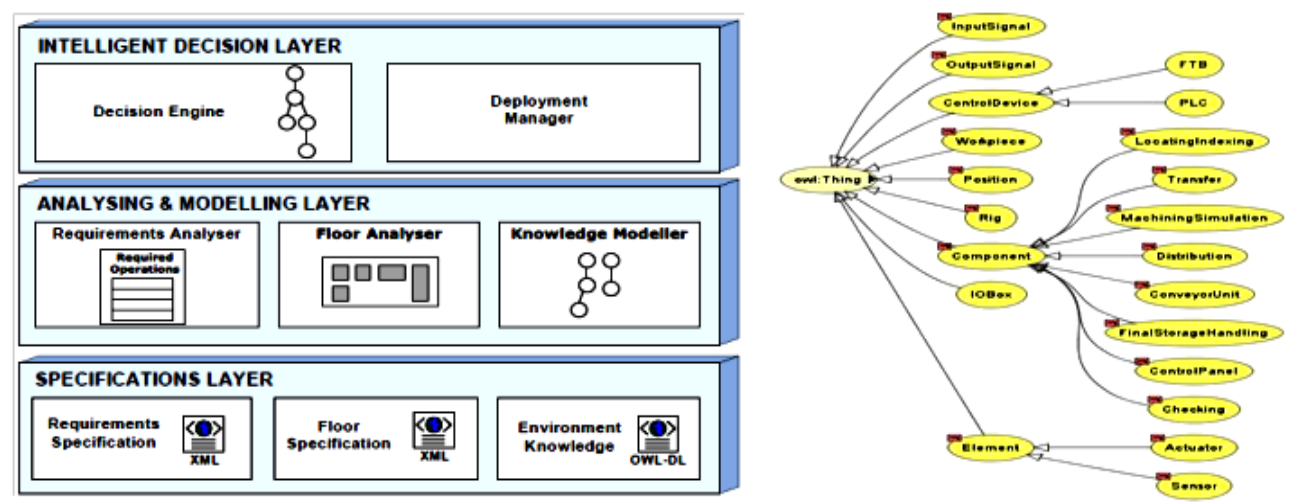

Figure 8. System layered architecture and the ontology of the PPR domains

Key concepts introduced into the ontology of the line are 'PLM Resource', 'PLM Product', 'PLM Resource Characteristics', 'PLM Product Parts' 'PLM Process' 'PLM Process Steps', OEM, Operator (manual resource) etc. For example, a certain workstation performs particular assembly tasks on specific products to achieve a definite objective. With the help of this knowledge in ontology, a quick evaluation of many potential configurations is possible as well as the best suited one for a changed product. With the help of this knowledge in ontology, a quick evaluation of many potential configurations is possible as well as the best suited one for a changed product.

\section{OnTOlOGical KNOWLEDGe BASEd SySTEM}

KBSs are computer software systems that work with justified true beliefs and are built for practical problem solving. The research focuses on the investigation and development of an ontology-based knowledge based system for the management of design and manufacturing 
knowledge in a distributed and collaborative environment for assembly line design and/or reconfiguration activity in automotive sector. Whenever there is any change in the product it is then essentially engineers responsibility to examine, verify and validate the needs of the reconfigured system to support the new product (Raza et al, 2011). To automate (fairly) the task of assembly line design and/or reconfiguration, product and resource link points need to be defined at early stages of design and made available easily to be searched, analysed and implemented on when and where required basis (Raza et al, 2011). Given that ontology has the potential to improve knowledge capturing, organization, sharing and re-use, it was chosen in this research to create a knowledge-based system to support the organization knowledge framework.

\subsection{Construction}

To design a KBS using the ontology technique is a multifaceted task. The approach in this job recommends a pathway of building a knowledge representation containing four actions.

The first step in KBS building is to outline a combined modelling language (UML) demonstration of the ontology and describe the relations between the concepts. The second action is to transform the UML class classification onto the application ontology using XMI and consequently create mappings of the responsibility and the perception in the ontology (Lin and Harding, 2003). The third step is to choose and configure suitable ontologies. In common, ontology creation is a tough procedure that needs the proficiency of knowledge engineers and field specialists. The awareness engineers and province specialist work as a squad to choose the recyclable theories and, if mandatory, adjust them and describe an agreeable dictionary to meet the demands of the submissions. The fourth and concluding step is to start the application ontology with domain awareness. While the application ontology illustrates which commencement is used in the domain, the significance knowledge illustrates the real example of these conceptions, that's why; this involves the domain specialists to assemble all compulsory knowledge to commission the domain ontology. The Figure 9 represents conceptual architecture of the PPR ontologies. The concepts are defined at abstract level, relationships established among concepts and basic hierarchical structure established.

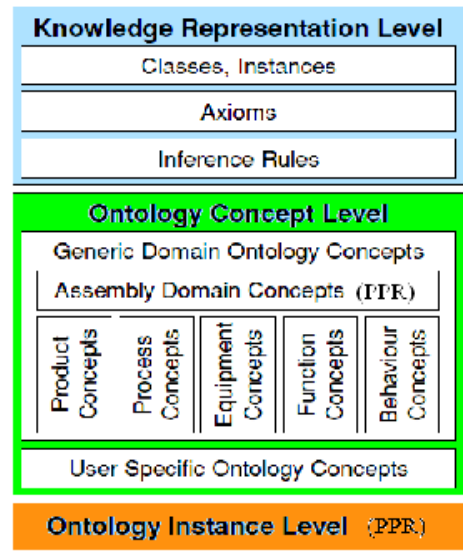

\section{PPR ON TOLOGY CONCHPI STRL CTURE}

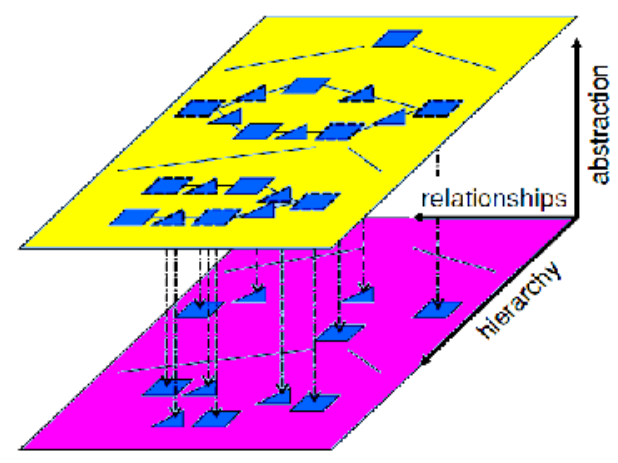

Figure 9. Structure of the Product Process and Resource (PPR) Ontologies

The left hand side of the Figure 7 depicts the three levels of ontology construction i.e. knowledge representation level, ontology concept level and ontology instance level. An example of concept and instance of the concept is shown below 


\section{Concept Resource}

name ofType string

performs ofType PD Process

hasProduct of Type PLM Product

\section{Instance Resource}

name hasValue "Station 500-CSA"

performs hasValue Crankshaft Assembly

hasProduct hasValue Crank Sub-Assembly

In this way all the relevant concepts were defined as classes with their instances in PPR ontology domains, a brief of which is shown in figure 7.

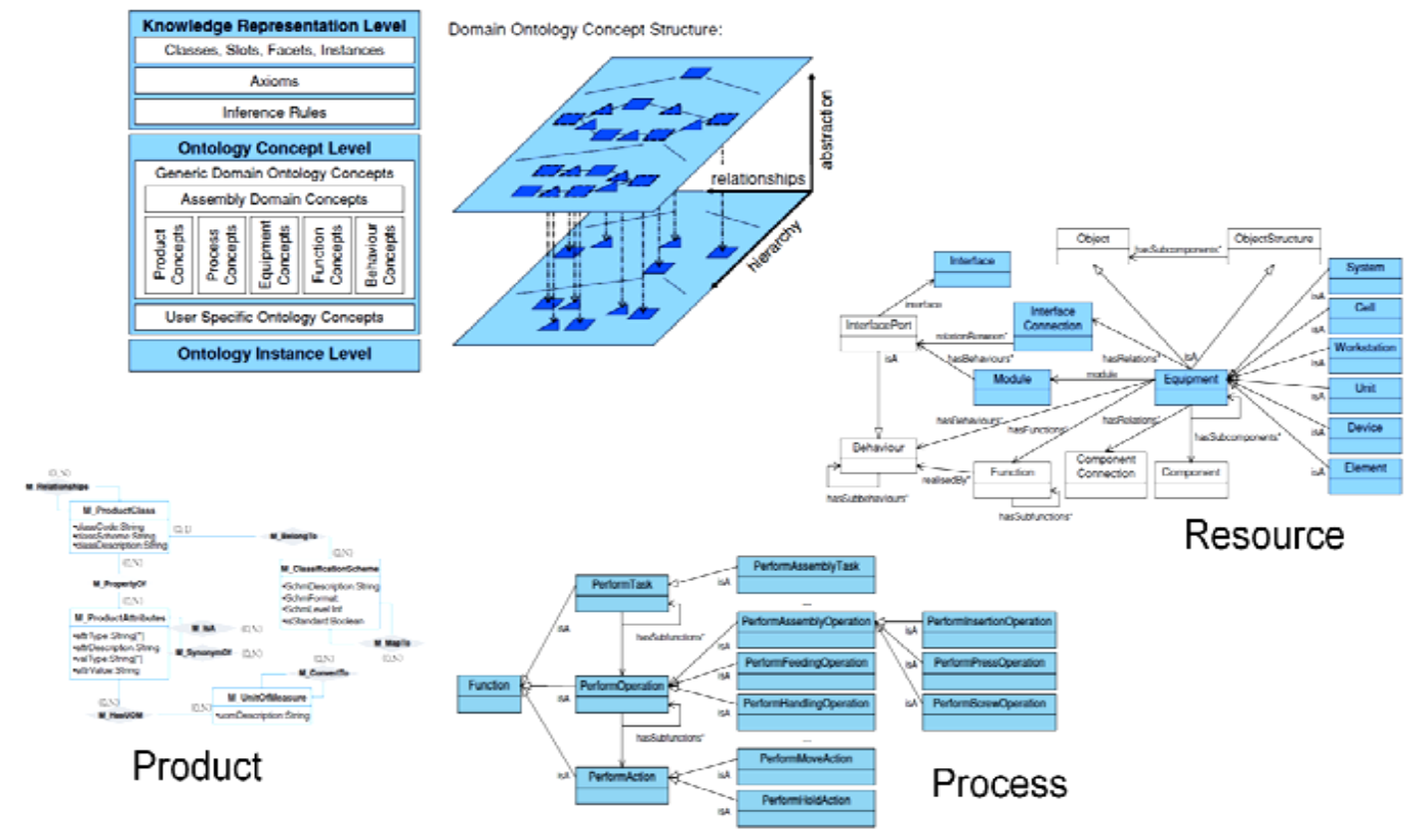

Figure 10. UML diagram of PPR domains and ontology building blocks

Any particular station of the engine assembly line can be decomposed to basic building blocks of modules of mechanisms which are independent to each other and can perform one operation independently. Different modules can be combined together to make a new station with changed process capabilities. These mechanisms are the building blocks of the extendable resources. Processes are the way the resources are and can be used. This relational dependency has been translated into ontologies as shown in Figure 10.

\subsection{Rules in OKBS}

The WSML syntax is split into two parts: (i) the conceptual syntax, and (ii) logical expression syntax. The general logical expression syntax for WSML has a first-order logic style. Additionally, WSML provides extensions based on F-Logic as well as Logic Programming rules and database-style integrity constraints

Based upon this, data was gathered, rules and restrictions formulated and translated into ontology. For example, the rule of length for powertrain is to use the standard length to minimize tooling cost. If greater length is required for additional power requirements, the maximum length cannot be exceeded without assembly feasibility study. In WSML ontology, it transforms to:

If Length $>\mathrm{x}$ Then actionA AND 
If Length $<\mathrm{x}$ Then action $\mathrm{B}$ AND

If Length $=\mathrm{x}$ Then actionC

In this way, several rules were constructed in the $\mathrm{KB}$ system based upon different key characteristics as recommended by the domain experts. The rule meta-model constructed for the current system is shown in Figure 11.

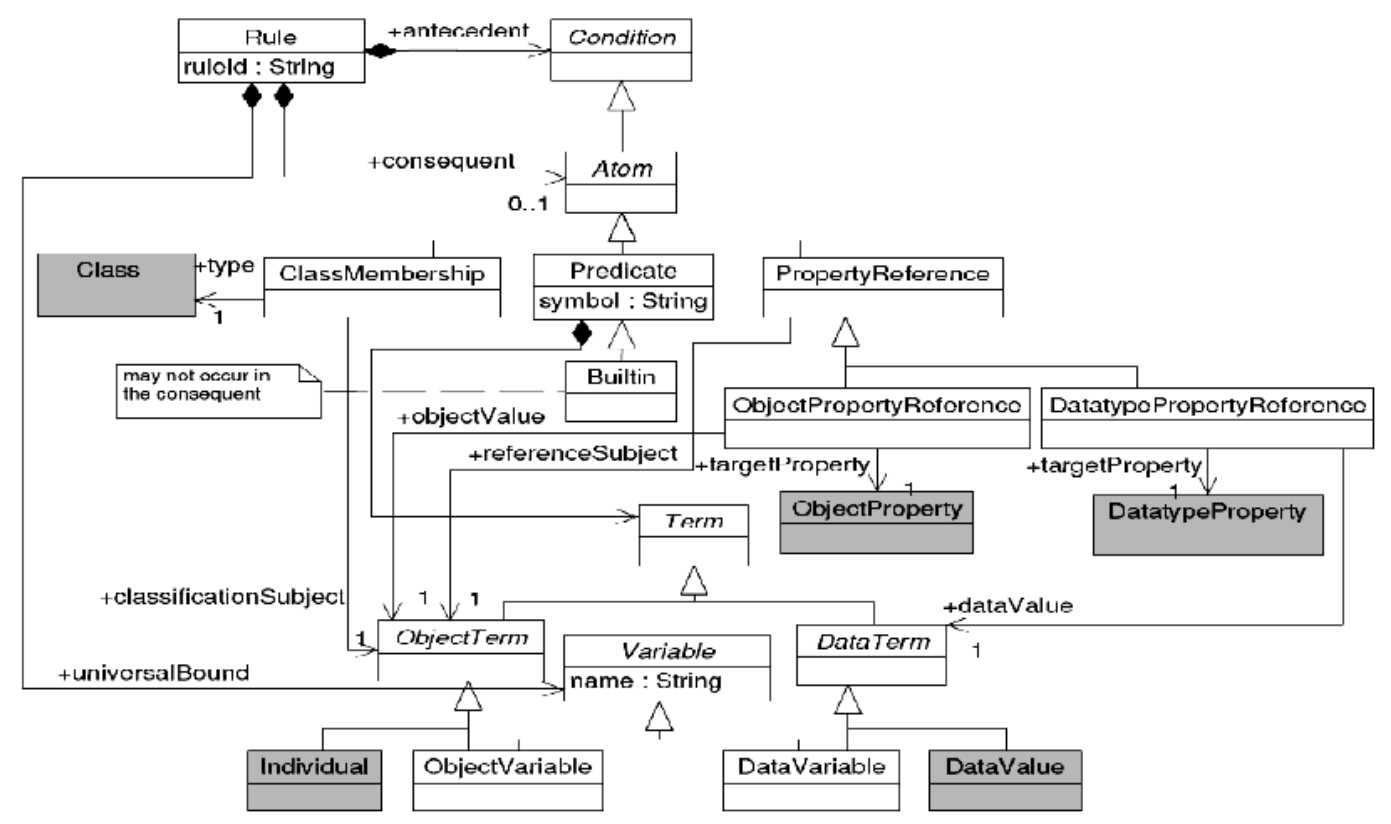

Figure 11. Rule meta-model for the developed KB system

An example of axiom formulation in WSML, used in the KB system, is as follows:

\section{Axiom Station100}

Defined by ?x member of Product AND

If

Product length < station Y-axis capability AND Product width $<$ station X-axis capability AND Product Height < station Z-axis capability AND Processes required within System capability AND Product Weight $<=$ max allowable weight on station Then Implies ?x member of Station50.

\section{IMPLEMENTATION OF THE KBS - CASE STUDY}

We advocate the idea of introducing ontology layer within legacy information management systems to integrate and facilitate the whole process. Ontology can serve the integration platform independent of software/hardware with formally defined semantics to use and reuse the information and knowledge generated along the business processes. 
Automotive engine assembly line is the case study for the current research. In this plant information of different products are stored and managed using Teamcenter. Main focus of Process Designer is on parameters and process sequence. FOM is used for managing "control programs. For multiple accesses and a better flow of information using a single query, focus is kept on product models which shows all the desired information of products and as a result helps in integrated design and manufacturing. It is intended to relate different product information to their respective processes and resources. The KB system uses ontology to model PPR information and combines object-oriented approach and first order predicate logic. With the help of first order logic, manipulation of relations between product assembly with regards to geometric constraints of machines is achieved. Using object oriented approach attributes of objects are represented in abstract way.

The structure and manufacture KB Systems encompassed with the use of the knowledge developing method for detaining early manufacturing know-how using the ontology, which was primarily constructed to form the domain using the UML. The UML class design was brought into the WSML ontology editor through (XML Metadata swapping management) XMI to generate the ontology. XMI is industry norm for affecting XML to theoretical systems such as UML. The purpose of XMI is to recommend a way to regulate XML for consumers to switch over information about metadata in circulated and varied surroundings (OMG 2005). An example of equipment ontology in terms of UML diagram is shown below in Figure 12.

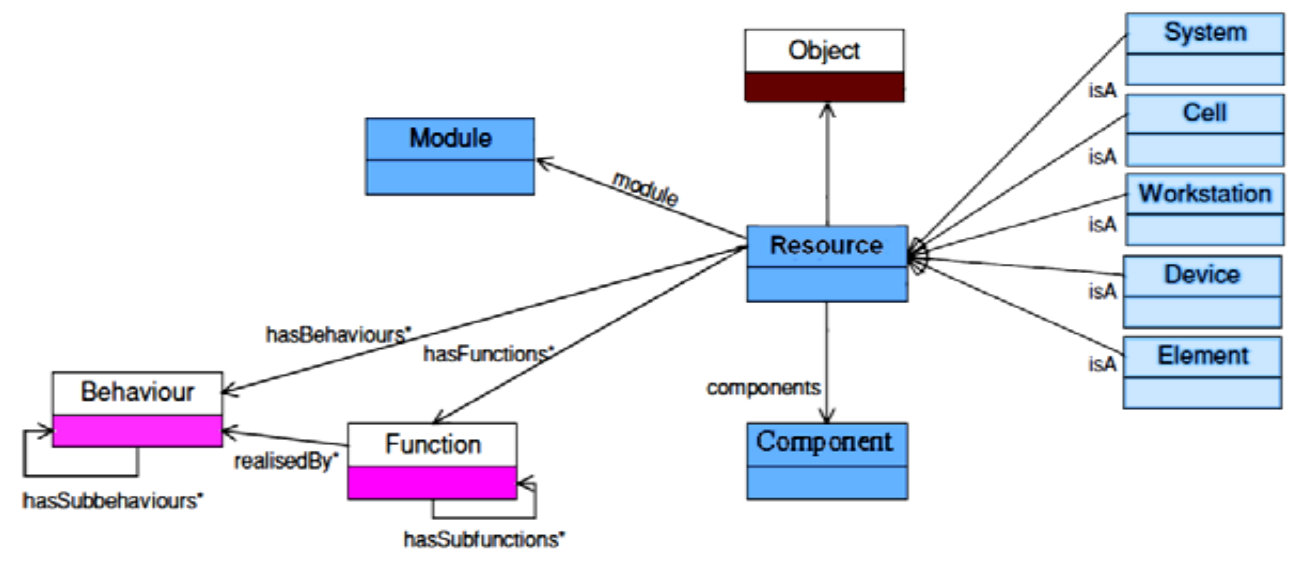

Figure 12. Conceptual construction of the Resource ontology

The equipment concept is a sub-class of object concept while module and component are subconcepts of equipment. With extra modification within ontology and by means of the ontology collection, vocabulary and restrictions were approved and the application ontology was created.. The design knowledge foundation was also developed by means of the similar method. The ontologies allow the data from the various design tools to be interrogated using the query engine. A Typical query into the engine could be what machines in line 1 can handle an engine that has 16 valves. The result will match the valve handling capacity of machines in the line and return the result. If some modules can't handle the new product design the tool can be used to find designs that can. 


\section{Current Results}

The authors have devised a collaborative production line planning solution based on knowledge management theories which was successfully implemented and the initial implementation results are extremely encouraging. Constraints evaluations were performed for automotive assembly line on the basis of information gathered from previous programs. Evaluation for assimilability of changed product with existing machines was performed and was found to be successful. Major focus of the KB system is on mapping the relations among PPR, these relations are defined using properties of concepts of ontology and the real world objects are defined using instances of concepts in ontology. As a result a formal definition of relations is established with all the relevant information about the models. Assembly machines at Dagenham acted as reference for new engines designs.

A Web Based Workbench specifically for PPR relations and their management and applications in assembly automation systems is done using KB system. Formal methods for classification of knowledge representation, acquisition were analyzed. Use of component based architecture has removed shortcomings for modelling, acquisition, knowledge representation and management. There are no platform independent application tools available for modelling the PPR information explicitly neither does any tool exist to link PPR relational information unequivocally. The developed knowledge based system is first of its kind for assembly line design / reconfiguration activity which is open, interoperable and platform independent. It also gives an extra value to 'Component Based' reconfigurable automation systems. Some of the benefits of the developed knowledge based system are:

- Reduced time and effort needed to reconfigure manufacturing systems in the event of changing requirements and conditions;

- Ability to extend integrated manufacturing enterprise models in a stepwise, flexible, and extendable way;

- Reduced system complexity and ease of reengineering processes;

- An advance in modelling MEs leading to practical implementation of the proposed modelling approach;

- A structured way of modelling static and dynamic aspects of manufacturing enterprises with induced change capability.

\section{CONCLUSIONS AND FURTHER WORK}

The existing information systems are improved with the help of knowledge bases (KB). KB has provided intelligence to these systems. Quality of information searching is improved and manual work is reduced. This is a practical approach and adds value to Component Based reconfigurable automation systems (Ontoprise, 2004). It leads to better visualization and an improved querying and addition of annotations. Idea is to lay the foundations of an extendable KB which could define PPR constraints that helps in rapid evaluation of dependency relationships and what will be their possible impacts. Knowledge base could be integrated with existing BPM systems at automotive sector. It also uses different techniques of artificial intelligence like neural networks, evolutionary computing techniques and uses multi-agent technology along with OKBS. Proof of concept has been applied in other sectors like aerospace industry. The proposed ontological knowledge system captures an initial, formal foundation by addressing different domain-specific requirements for knowledge bases specifically related to PPR. The solution is not restricted to a single ontology and rule language. It is open future standards in that area (Davies.et.al, 2002). It depends on the used infrastructure and transforms concrete models to the required representation language. The central ontological is used for building a highly modularized framework for 
supporting the development and management of knowledge bases. The methodologies developed can easily be extended or reused for supporting particularities of specific formalisms. The continuation of the work consists of including other downstream application tools in the ontology as well as enhancing the scope from line designing / reconfiguration to other knowledge intensive activities including line simulations and resource productivity analyses. The recently started AESOP (ArchitEcture for Service Oriented Process Monitoring and Control) project is now extending the current research results in the process control domain.

\section{ACKNOWLEDGEMENTS}

The authors gratefully acknowledge the support of the UK EPSRC and Loughborough University's IMCRC through 'BDA' and 'AESOP' projects. We would like to thank all the project participants and engineers who have contributed in this research from Loughborough University and participant companies especially Ford Motor Company, UK.

\section{REFERENCES}

Abecker, A., Mentzas, G., Legal, M., Ntioudis, S., \& Papavassiliou, G. (2001). Business process-oriented delivery of knowledge through domain ontologies. In Second international workshop on theory and applications of knowledge management (pp. 442-446). Munich.

Baker, R.P. and Maropoulos P.G., Manufacturing capability measurement for cellular manufacturing systems. Int. J. Prod. Res., 1999, 36, 2511-2527.

CIMdata (2007). Product Lifecycle Management (PLM) Definition. http://www.cimdata.com/PLM/plm.html Accessed on 16.06.2011.

Ciocoiu, M., Gruninger, M. and Nau, D.S., Ontologies for integrating engineering applications. J. Comput. Info. Sci. Engng, 2001, 1, 12-22.

Dalkir, K. (2005). Knowledge management on theory and practice. Burlington, MA, USA: Elsevier pp. 1920 .

Davies, J., Fensel, D. and van Harmelen, F., On-to-Knowledge: Semantic Web enabled Knowledge Management, 2002 (John Wiley, UK).

Davis, M. (2006). Semantic Wave 2006 - Executive Guide to Billion Dollar Markets. Project10X, Special Report.

Duineveld, A.J., Stoter, R., Weiden, M.R., Kenepa, B., and Benjamins, V.R.: WonderTools? - A comparative study of ontological engineering tools, International Journal of Human-Computer Studies, Vol. 52, 2000.

Fensel, D. et al. (2006). Enabling Semantic Web Services: The Web Service Modeling Ontology. SpringerVerlag Ltd.,London,.

Garcia-Solaco, M. and Saltor, F. and Castellanos, M. Semantic Heterogeneity in Multidatabase Systems. Object-oriented Multidatabase Systems: A Solution for advanced Applications, 129-202, 1999

Gerd Stumme, Marc Ehrig, Siegfried Handschuh, Andreas Hotho, Alexander Maedche, Boris Motik, Daniel Oberle, Christoph Schmitz, Steffen Staab, Ljiljana Stojanovic, Nenad Stojanovic, Rudi Studer, York Sure, Raphael Volz, and Valentin Zacharias. The Karlsruhe view on ontologies.

Gruninger M., K. Atefi, M.S. Fox, Ontologies to support process integration in Enterprise Engineering, Computational and Mathematical Organization Theory 6 (2000) 381-394.

Gunasekaran, A. (1998). "Agile manufacturing: enablers and an implementation framework." International Journal of Production Research 36(5): 1223-1247.

Hahn, A. (2007). Using Ontologies to Model and Understand Product Development. IBIS -Interoperability in Business Information Systems, 5, 21-39. 
Hammer, M. and J. Champy (1993). Re-engineering the corporation: a manifesto for business revolution. New York, Harper Business.

Harrison, R. (2006). Lifecycle engineering of future automation systems in the automotive powertrain sector.In: IEEE International Conference on Industrial Informatics, 305-310.

Hepp, M. (2007). Ontologies: State of the Art, Business Potential, and Grand Challenges. Ontology Management: Semantic Web, Semantic Web Services, and Business Applications, Springer, 3-22.

Hirani H (2004) Knowledge enriched requirements specification for reconfigurable assembly systems, $\mathrm{PhD}$ Thesis, University of Nottingham, 2004

IBROW3(2004), An Intelligent Brokering Service for Knowledge-Component Reuse on the WWW, Available : http://www.swi.psy.uva.nl/projects/IBROW3/home-ibrow.html [Accessed on 19 March 2011]

Jones, D. H. and Uschold, M. (2005). Role of Rules and Rule Interchange in Semantic Integration \& Interoperability. In Proceedings of the W3C Workshop on Rule Languages for Interoperability,27-28 April 2005, Washington, DC, USA.

Küsters, K. (2006). Teilautomatisierte Überführung der Produktstruktur in eine lastfallabhängige Modellstruktur mittels Ontologien. Diplomarbeit Rheinisch-Westfälische Technische Hochschule Aachen.

Lin, H.K. and Harding, J.A.( 2003) An ontology driven manufacturing system engineering moderator for global virtual enterprise teams. Proceedings of the 1st International Conference on Manufacturing Research (ICMR), Glasgow, UK, 2003, pp. 365-370.

Lohse N., Ratchev S., Chrisp A. (2004) Function-behaviour-structure model for modular assembly equipment. pp 167-174,2004

Mizoguchi R, Kitamura Y (2000) Foundation of knowledge systematization: role of ontological engineering. in: Roy R(ed) Industrial knowledge management: a micro-level approach. Springer-Verlag Ltd.,London, ISBN 1852333391

Moench, E., Ullrich, M., Schnurr, H.P. and Angele, J., Semantic(2003) Minerontology-based knowledge retrieval. J. Univers. Comput. Sci., 2003, 9,682-696.

Noy, N.F. and Klein, M.C.A.(2004), Ontology evolution: not the same as schema evolution, Knowledge and Information Systems, pp. 428-440, 2004

Noy N.F., D.L. McGuinness, Ontology Development 101: A guide to Creating your First Ontology, Stanford Medical Informatics Technical Report No. SMI-2001-0880, 2000. URL: www.smi.stanford.edu/projects/protege/publications/ontology_development/ontology101.pdf.

OKT(2004). Onto Knowledge, Available online at: http://www.ontoknowledge.org/indexShtml [Accessed on 19 March 2011]

OMG ( 2005), On the road, Available online at: http://www.omg.org, [Accessed on 20 March 2011]

Object Management Group (2003). Ontology Definition Metamodel - Request For Proposal.

Ontoprise (2004), Ontology Concepts, Springer, 3rd edition. http://www.ontoprise.de/products/ontobroker_en accessed 16.06.2011.

Prot'eg'e (2004) Stanford University, Stanford University School of Medicine, Stanford Medical Informatics,California, USA, available at: protege.stanford.edu

Raza M. B., Harrison R., 2011a, Information Modeling and Knowledge Management Approach to Reconfiguring Manufacturing Enterprises, International Journal of Advanced Information Technology (IJAIT) Vol. 1, No. 3, 2011.

Raza M. B., T. Kirkham, R. Harrison, 2011a, Knowledge Based Flexible and Integrated PLM System at Ford, Intl. Journal of Information \& Systems Management, Volume 1, Number 1, 2011.

Raza Muhammad B., Kirkham T., Harrison R., 2010, Knowledge Based PLM System, Journal of ETechnology, Volume: 1, Issue: 2 (May 2010), Pages: 66 -74 
Raza M.B., R. Harrison, 2011b, Intelligent Integration of Product Design to Production Devices, Proceedings of the International Conference on Information and Knowledge Engineering, World Congress in Computer Science, Computer Engineering and Applied Computing, Las Vegas, Nevada, USA, July, 2011.

Raza Muhammad Baqar, Robert Harrison, 2011c, Ontological Knowledge Based System for Product, Process and Resource Relationships in Automotive Industry, Proceedings of the 1st International Workshop on Ontology and Semantic Web for Manufacturing, co-located with the 8th Extended Semantic Web Conference, ESWC2011, Heraklion, Crete, Greece, May 29, 2011.

Raza Muhammad. B., T. Kirkham, R. Harrison, Q. Reul, Knowledge Based Flexible and Integrated PLM System, International Journal of Computing Architecture, Volume 4, Issue 2, July 2009

Raza, M.B. Kirkham, T. and Harrison, R. (2011b) 'Embracing knowledge driven devices: service oriented standardisation of production management in automated lines', Int. J. Service and Computing Oriented Manufacturing, Accepted and in press.

Roche, C.,:Corporate ontologies and concurrent engineering, Journal of Materials Processing Technology, Vol.107, 2000, p.187-193.

Roman D., U. Keller, H. Lausen, R. L. Jos de Bruijn, M. Stollberg, C. Feier, C. Bussler, and D. Fensel. Web Service Modeling Ontology. Applied Ontology, 1(1):77-106, 2005.

Schlenoff, C., Gruninger, M., Tissot, F., Valois, J., Lubell, J. and Lee, J.(2000) The process specification language (PSL) overview and version 1.0 specification. NISTIR 6459, Gaithersburg, MD, 2000

Sowa, J.F(1995), Top-level ontological categories. Int. J. Human-Comput. Studies, 1995, 43, 669-685.

Staab, S. (2002). Wissensmanagement mit Ontologien und Metadaten Habilitation Thesis, University of Karlsruhe.

Stegmüller, H. (2003). Zeit fürs Wesentliche - Audi erprobt semantische Technologien. Digital Engineering Magazin, 4, 44-45.

Stevenson, M., L.C. Hendry and B.G. Kingsman (2005). "A review of production planning and control: the applicability of key concepts to the make-to-order industry." International Journal of Production Research 43(5): 869-898.

Syldatke, T. et al. (2007). How Ontologies and Rules Help to Advance Automobile Development. Advances in Rule Interchange and Applications. International Symposium, RuleML 2007, Orlando, Florida, October 25-26, 2007, Proceedings, Invited Paper, 1-6.

Turban, E. and Aronson, J.E. (2000), Decision support systems and intelligent systems, 2000, (US Imports \& PHIPEs).

Uschold M., M. Gruninger, Ontologies: principles, methods and applications, Knowledge Engineering Review 11 (2) (1996), June.

Valarakos, A., Paliouras, G., Karkaletsis, V. and Vouros, G.(2004), Enhancing ontological knowledge through ontology population and enrichment.2004, Vol. 3254, pp. 144-156 (Springer Verlag, New York).

Van Heijst G., Schreiber A.T. and Wielinga B.J(1999), Using explicit ontologies in knowledge-based systems development. Int. J. Human-Comput. Studies (IJHCS), 1999, 46, 183-291. 


\section{Authors}

Dr. Muhammad Baqar Raza has completed his $\mathrm{PhD}$ from Loughborough University, UK. His PhD research is about ontological knowledge management techniques for manufacturing and automation systems especially in automotive sector. He did his BSc in Mechanical Engineering from UET, Pakistan, obtained his MSc degree in Product Engineering from Cranfield University, UK. He worked for more than 08 years in various industrial domains in different capacities, including shop-floor supervisor, quality engineer, production engineer and research collaborator. His research area includes manufacturing knowledge management, service oriented computing, quality control, quality management systems and implementation of lean-6sigma techniques in automotive and aerospace sectors.

Prof. Dr. Robert Harrison is a Professor at Loughborough University. $\mathrm{He}$ is head of the Virtual Automation Research (VAR) Group specialising in the virtual engineering, deployment and remote support of automation systems in manufacturing and related domains. $\mathrm{He}$ worked with British Aerospace, Aircraft Group, seven years of industrial experience with British Aerospace working on real-time distributed systems. Visiting Research Fellow at the National University of Singapore. He did his $\mathrm{PhD}$ in distributed machine control systems from Loughborough University. Ford Motor Company Research Fellow from 1996 to date. Research focused on systems modelling, integration and control. Creating globally distributed virtual environments to underpin the life cycle engineering of component-based machines and process control systems. The VAR Research Group is currently collaborating with the Ford, Mazda, Jaguar and leading automotive machine builders to develop the next generation of machine design, control and monitoring systems for future factory automation systems.
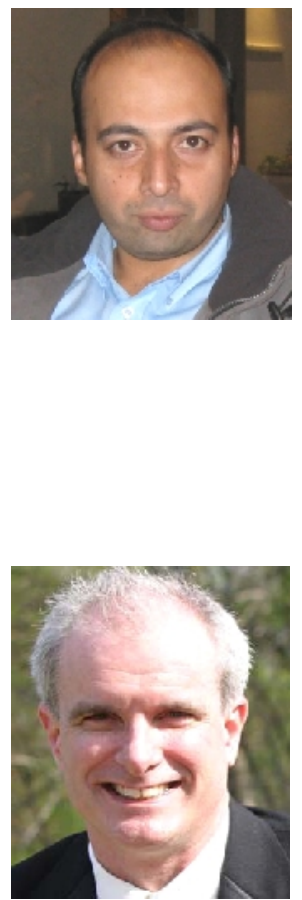